\begin{tabular}{|c|l|l|l|l|l|}
\hline$\wedge$ & ETHO & etho12132 & Dispatch: June 7, 2016 & CE: $\mathrm{XXX}$ \\
\cline { 2 - 6 } & Journal & MSP No. & No. of pages: 21 & PE: $\mathrm{XXXX}$ \\
\hline
\end{tabular}

202 ETHOS

\title{
New Studies of Children's Work, Acquisition of Critical Skills, and Contribution to the Domestic Economy
}

\author{
David F. Lancy
}

\begin{abstract}
In spite of the fact that the very earliest ethnographers who paid any attention to children took note of the "precocity" displayed by children in both learning the household (e.g., caring for a younger sibling) and subsistence (harvesting and processing grain), tasks characteristic of the societies under investigation, the first synthesis and cross-cultural compilation of this large body of descriptive material is quite recent. This first, introductory, article in this collection reviews those efforts to systematize the study of children's work and leads the reader through a catalog of the major conclusions or generalizations that have emerged from this analysis. To take a single example, the ethnographic record shows clearly that the work children do, whether differentiated by age, gender, or competence, serves, in large part, to shape their emerging identity. The Introduction then proceeds to forecast the following three articles, all of which advance significantly beyond our current understandings. A finer-grained analysis reveals significant cross-cultural variation around many of the generalizations made earlier regarding how children become helpers and workers. [child development, childhood, childrearing, community, cultural models, ethnography]
\end{abstract}

\section{Paying Attention to Children's Work}

Contrary to Hirschfeld's (2002) claim that "Anthropologists Don't Like Children," childhood was an early interest of psychological anthropologists (DuBois 1944; Malinowski 1929; Mead 1928; Whiting 1941). This interest has continued and even increased recently (Lancy 2015). The growing volume of anthropological research on childhood notwithstanding, the lack of comparative analyses and theory development (conceded largely to the discipline of psychology) has provided some justification for Hirschfeld's argument. However, this omission is now being addressed (Lancy et al. 2010). As interest has grown, and research expanded on the varied cultural contexts for child development, lacunae have been revealed. Prominently, these include the study of children's work (Nieuwenhuys 1996) and, by extension, the processes underlying children's acquisition of critical work skills.

This neglect may be attributed, at least in part, to the fact that the majority of childhood scholars, regardless of discipline, operate within one particular-even "WEIRD" (Henrich et al. 2010)—culture. In Western, Educated, Industrialized, Rich, Democratic (WEIRD) society, children are prohibited from "laboring" for wages and contribute little to the maintenance of the household (Klein and Goodwin 2013; Ochs and Izquierdo 2009). ${ }^{1}$ Rogoff (2014) and colleagues (Alcalá et al. 2014) have documented the transition from indigenous Mayan 
communities where modernization and acculturation have been minimal to "cosmopolitan," urban communities nearby. In the former, children eagerly do chores; in the latter, they are actively prevented from helping. In WEIRD society, children's "work" is nested within the tasks associated with schooling (Qvortrup 1994:36) and within adult-directed, extracurricular activity, such as music lessons and sports (Kremer-Sadlik et al. 2010).

This "work" serves to foster the child's own development and, far from relieving others of their burdens, it adds to the parents' workload in several respects. A prototypical case that illustrates this reversal (parents working for children rather than the reverse) comes from a study of middle-class Scottish families where "Mum cleaned it (the pet), I just played with it (Muldoon et al. 2015:201). "There was a widely held belief that young children lacked knowledge of how to look after animals properly and needed to be taught or 'trained' [hence] ... children ... were 'not allowed' to do certain things for the animal" (Muldoon et al. 2015:210).

Outside WEIRD society, children are typically engaged in an extremely wide range of activities that could be labeled "work." ${ }^{2}$ Tasks like fetching water, caring for younger siblings, cleaning, gardening, and taking care of livestock are the necessary adjuncts of domestic life (Whiting and Whiting 1975:84). Chores may be adopted voluntarily by children or assigned by a parent (Stieglitz et al. 2013). From toddlers to teenagers, children are expected to help out according to their capacity and skill. Scholars have taken care to designate "children's work" as the tasks that are incorporated into family life and are "developmental," where children are learning while helping. In contrast, "children's labor" for wages, or to work off a family debt may involve removing a child from its family, exposing him or her to arduous and unhealthy conditions, and may not include opportunities for learning and advancement. In short, "labor" is usually detrimental to children, at least in the long term (Bourdillion and Spittler 2012: 9).

\section{How Children Become Workers}

The question of how children learn the foundation skills (or, more broadly, their culture) in order to make a significant contribution to their family's resources has received increasing attention. In deductive lab studies with chimpanzee and Euroamerican children as subjects, psychologists have identified the evolved mechanisms that even very young children deploy in this process, such as imitation and emulation (Konner 2010:720-722). Psychological anthropologists have utilized cross-cultural comparisons, spot observation, elicitation of parental ethnotheories, and ethnography (e.g., Keller 2007; LeVine 2007) to derive, inductively, models of the learning process. Summarizing the "Six Cultures" studies undertaken in the mid-50s, the Whitings claim that:

... skills are more likely to come from observation than from instruction. It should not be assumed that parents play an entirely passive role in the socialization process. It is in the assignment of tasks and the punishment of disobedience rather than in either deliberate instruction or rewarding and punishing specific behaviors that they have the greatest effect. $(1975: 180)$ 
204 ETHOS

One of the most thoroughly studied and influential models of children learning their chores has been developed by Barbara Rogoff and her colleagues—characterized as "learning by observing ${ }^{3}$ and pitching in," or LOPI. LOPI includes both intense, wide-angled, yet passive observation (Gaskins and Paradise 2010) and learning through participating as a novice in cooperative or joint-work activities. For example, the Yukaghirs' (Siberian foragers) "model of knowledge transferal could be described as doing is learning and learning is doing" (Willerslev 2007:162).

Rogoff notes: "[LOPI] seems to be widely used in Indigenous-heritage communities of the Americas and may be common in other parts of the world" (2014:71). Ethnological surveys encompassing the corpus of ethnographic studies of childhood (Lancy 2015) would generally affirm this latter generalization. However, recent studies suggest LOPI may not be universal or is attenuated compared to Rogoff and colleagues' indigenous American communities. The articles in this collection all reflect a careful analysis of children learning and working in specific, relatively unacculturated communities, and all reveal this attenuation.

The following article by Medaets is based on her fieldwork in the Lower Tapajós River of Brazil. These communities subsist on a mix of foraging, including hunting and fishing and horticulture. Economic support is also provided by the government. Medaets focuses her attention on children exhibiting the skills commonly employed in the aforementioned subsistence processes and their movement from incompetent novice to helpful practitioner. As in the indigenous American communities, Tapajós villagers do expect their children to pitch in and be helpful. However, children cannot always depend on opportunities to observe and pitch in. With respect to the former, aspirant hunters must learn largely on their own with some input from older peers because their fathers spurn their accompaniment on hunting forays. With respect to the latter, adults seem to have little patience with clumsy novices who are as often ridiculed as encouraged in their fledgling attempts. Hence, in order for Tapajós children to become full, appreciated members of the domestic labor unit, they must strive to learn independently, relying mostly on observation and discreet practice which may include unauthorized "borrowing" of adult tools.

The Mongol herders studied by Michelet move between communities of two types, remote family clusters of yurt-dwelling herders (varied stock, including camels) and communities with at least some permanent facilities such as clinics and schools but no animal herds. So, in the latter, children learn and help out with animal husbandry during holiday periods and also are expected to contribute to maintaining the home year-round. The family unit is two to three generations, and grandparents may participate in child care. As is true across the spectrum of traditional small-scale societies (see the general discussion below), Mongol children are not impeded from observing everything and everyone at home, in the community, corrals, and pastures. Children readily volunteer to help out, but they may be rather sharply rebuffed by their elders with the expression "chi chadabgui!"or "you can't do it." The injunction might be interpreted as a warning to the child to observe, practice, and become competent in a particular skill before volunteering. It also might act to motivate the child to try harder. Conspicuously, the adult does not immediately respond by assisting 
the child or trying to "scaffold" his or her efforts. Motivation becomes a problem also with older children who, although fully competent, may become reluctant to shoulder routine chores and thus become the targets of adult exhortation. In documenting this early decline in children's work, Michelet highlights a society that departs somewhat from the indigenous American pattern as documented by Rogoff and others (Rogoff et al. 1993). In Kramer's studies of Mayan peasant children, for example, she finds that they continue to provide critical support for the family until their late teens when they marry: "Without the contributions of their children, Maya parents would have to double or triple their work levels beyond observed values" (Kramer 2005:168).

In the concluding article in the collection by Little and Lancy, these themes are addressed as well as the question of data collection and analysis. Several recent studies probing the processes through which children acquire critical work skills claim that this happens largely via deliberate instruction of children by parents (e.g., Kline et al. 2013)-quite different from the LOPI model. But serious doubts have long been raised about the use of retrospective interview data in making inferences about behavior. For example, LeVine recalls that the use of retrospective interviews in the Six Cultures studies from the 1950s "came under devastating empirical critique in the psychological literature" (2010:518). Our critical analysis of the exclusive reliance on interview data is based primarily on Little's work with Asabano parents and children. The Asabano-sweet potato and pig growers and foragers from the remote Telefomin District of the PNG Highlands - are, certainly, the least acculturated of the three societies, which are the focus of this collection. Little, whose intent it was to study the contributions of children as increasingly skilled helpers, was struck with a paradox. Interviews with parents suggested unequiyocally that they were wholly responsible for teaching children all the necessary skills to become a competent Asabano adult. On the other hand, Little's ethnography and further questioning of adults and children regarding their work showed that no such explicit teaching occurred. ${ }^{4}$ In fact, similar to the Tapajós communities, parents did not show much recognition let alone appreciation for their children's useful and competent services-learned autonomously. And, again, fathers and adults, generally, play almost no role in the socialization of young hunters. The article concludes with a general discussion of the need for a solid ethnographic base that takes into account local discourse patterns, social relations, ethos, and acculturation, among others, in order to create a robust context within which interviews may be meaningfully designed and used as data.

In the sections that follow, I provide a broad survey of research on the development of children in societies where they play important roles in the domestic economy.

\section{Work as the Locus of Children's Development}

As ethnographers have paid increasing attention to children's work and their roles in the family and community, the archive of cases in cultural and psychological anthropology (Bolin 2006; Greenfield 2004; Orellana 2001; Rogoff 2003; Spittler 1998) as well as history, (e.g., Clement 1997) have reached the level where we can begin to hazard some generalizations. ${ }^{5}$ In this introductory essay, I will review those generalizations and the basis for drawing 
206 ETHOS

them. This will include a focus on children as well as on their parents, who are both role models and taskmasters. To that end, the parental ethnotheory (set of beliefs or moral assumptions) that frames children's work will be explored. The "cultural models" concept proposes that societies incorporate templates or models to guide members (Quinn 2005:479; Strauss 1992:3) that include customary practices, sanctions for following or not following those practices, and an ethnotheory that organizes these ideas and provides an overarching perspective (Super and Harkness 1986). The Hindu ethnotheory of infancy, for example, recognizes three distinct stages characterized by the child's diet and change in diet over time (Keller 2007:111). Ethnotheories have "directive force," meaning that they direct behavior (Harkness et al. 1992) and identify and correct (or sanction) misbehavior. For example, most societies embrace the notion that children should willingly volunteer to do chores. The Giriama of Kenya assert that a child learns to respect others and develop responsibility by working. A mother "who does not expect her children to help is remiss, even neglectful" because her children will grow up without the support and respect of the community (Wenger 1989:93). As the Little and Lancy article in this collection shows, however, parental ethnotheories are subject to change in response to larger social changes that occur, and there may be a fairly wide gulf between theory and actual practice.

\section{Little Helpers}

Anthropologists often note, with some degree of awe, just how young children are when they begin to "pitch in" (Paradise and Rogoff 2009). On Raroia, a four-year old equipped with a suitably sized container, may make as many as 10 trips per day, carrying water from the community cistern to his home (Danielsson 1952:121). I have often observed youngsters (Lancy 2015, Figure 21:255) no older than five, carrying and looking after infants (see also Ottenberg 1968:80). On Samoa "the tiniest little staggerer has tasks to perform-to carry water, to borrow fire brands, to fetch leaves to stuff the pig” (Mead 1928:633). These examples can be readily multiplied (Edel 1966:178; Gottlieb 2000:87; Marlowe 2010:198; Ohmagari and Berkes 1997:206; Rival 2000:116), and it seems clear that, regardless of geography, culture, or subsistence type, we can expect to see children volunteering to assist with household tasks. This assertion was supported by a psychology experiment in the United States that simulated a home environment where mothers and fathers were carrying out various tasks with young children in attendance (and more recently replicated in Germany: Warneken and Tomasello 2006:1301). Children as young as 18 months of age:

spontaneously and promptly assisted the adults in a majority of the tasks they performed. Furthermore, the children accompanied their assistance by relevant verbalizations and by evidence that they knew the goals of the tasks, even adding appropriate behaviors not modeled by the adults. (Rheingold 1982:114)

In most societies, work is as prominent as play in children's lives, and systematic study of Kpelle children working led me to posit the existence of a "chore curriculum" (Lancy 1996:144). The term "curriculum" conveys the idea that there is a discernible regularity to the process whereby children attempt to learn, then master, and finally carry out their 
chores. The academic or "core" curriculum (of Math, English, Science) found in schools is formal and imposed on students in a top-down process. The chore curriculum, by contrast, is informal and emerges in the interaction of children's need to fit in, and to assist and emulate those older (Bandura 1977; de Waal 2001:230-231), with their apparent drive to become competent and feel efficacious (White 1959:329), their developing cognitive and sensorimotor capacity (Lancy and Grove 2011), the division of labor within the family and, of course, the nature of the tasks (chores) themselves.

But, even before children are mature enough to be accepted as "legitimate peripheral participants" (Lave and Wenger 1991), they may begin the process of learning their chores through play.

\section{The Play Stage}

One important conclusion we can draw from the literature on children's work is that it is almost always foreshadowed in play. In fact, the play stage is finessed only when the child is assigned a chore, such as caring for a baby brother, even before they've begun to play with dolls (Broch 1990:110) or permitted to participate in animal care (at three years of age) without doing it first in make-believe (Michelet, this issue). Ethnographic descriptions of work activity replicated in make-believe are rich and varied. In the domestic sphere, we see children playing at food preparation, building houses, and making mats and furnishings (Hogbin 1969:38; 1970:137). Mayan weavers in Nabenchauk had nearly all done play weaving when they were little (Greenfield 2004:37). Inuit girls make dolls and clothe them out of scraps of skin. "Their mothers encourage them, for it is in this way that they learn to sew and cut out patterns" (Jenness 1922:219).

While parents are almost never observed playing with children postinfancy (Lancy 2007), instances of parents giving toddlers cast-off or miniature tools to play with are legion (Tayanin and Lindell 1991:15), but not by any means universal, as the Medaets' article following demonstrates. The presence of crudely made or small-scale artifacts, such as flint points, offer a rare glimpse of childhood in archaeological work (Kenyon and Arnold 1985). The smooth transition from the play stage to more productive work is evident in Hadza children.

Children spend most of their time in mixed-sex play-groups in camp or just outside... watching 3-4 year-olds playing a while, one eventually realizes that [they] are not just playing but are actually digging small tubers and eating them ... foraging simply emerges gradually from playing and involves very little teaching. It involves a natural interest on the part of the young child watching older people forage and imitating them. Girls 4-8 years old bring in 361 daily kcals, which is about $25 \%$ of their requirements. Boys [somewhat fewer]. (Marlowe 2010:156)

Not only is the transition from play to work seamless, children engage in their chores with a playful demeanor. For example, "one of the most striking aspects of [Sudanese] children's lives was the fusion between the activities of work, play and learning" (Katz 1986:47). 
208 ETHOS

While children are generally expected to begin learning the suite of skills associated with particular domains of work, often starting with running errands (Lancy 2012a:29-30), through carefully watching competent actors and playful imitation of what they've observed (Chick 2010), many societies support what has been referred to as "intent community participation" (Paradise and Rogoff 2009:104). These are situations where children are welcome to join collaborative work routines, involving one or more others, and where some piece or component of the routine falls within their capabilities.

\section{Learning in the Family Circle}

A key factor in the ease with which children learn socially is that "culture" is largely an "open book." The "curriculum" confronting a child in the village is not concealed behind doors, in books, or in people's heads. For the most part it is made freely available: "No [Tallensi] would inhibit his conversation or actions because children are present (Fortes 1970:37)." Similarly, Biyaka children who must learn a mix of foraging and gardening skills:

have almost ubiquitous opportunity for observational learning of adult subsistence behaviors. Furthermore, "watching" a behavior that is necessarily the commencing act of any visual observational learning, was a very high-frequency activity across all age groups. (Neuwelt-Truntzer 1981:109)

Another aspect of this openness and ready access to learning opportunities is that traditional, small-scale societies, unlike WEIRD society, incorporate economic or subsistence activity within the family circle. Production is rarely separate. ${ }^{6}$ From the earliest habitation sites found to date, we see a pattern of humans working in a public setting with multiple participants and onlookers including, especially, children. Studies of the stone scatter from sites where stone tool production occurred show incomplete or poorly made tools and debris consistent with a mixture of skill levels, including beginners (Dugstad 2010:70). At two Magdalenian sites in France, "highly skilled knappers occupied places closest to the hearth, the less skilled knappers and the novices sat further back from it" (Shennan and Steele 1999:375). In a contemporary village scene, Matsigenka "infants and young children are embedded in the middle of quotidian activities where they are positioned to quietly observe and learn what others are doing" (Ochs and Izquierdo 2009:395). Medaets describes a Breugelian tableau in an Amazonian village (see Figure 1 in Medaets' article, this issue) where a family of mixed ages, with no fewer than eight children aged 4-15, is busily working in a sociable cluster around the house. Everyone, including the youngest, has a task drawn from the component parts of manioc processing or clean-up (Medaets 2011:3). Ingold characterizes this kind of activity as follows:

In the passage of human generations, each one contributes to the knowledgeability of the next, not by handing down a corpus of disembodied, context-free information, but by setting up, through their activities, the environmental contexts within which successors develop their own... skills. (2001:142) 
West African girls learning to hull or pulverize grain in a mortar and pestle will first play at the task using grass or some other expendable material. Once the child can be trusted not to spill the grain while hulling it (Bock and Johnson 2004), she will be given a scaled-down mortar and pestle and partnered with an older expert who, while not explaining or instructing, will adjust her rhythm and stroke to the child's (Bril 1986:325). This minimalist "scaffolding" by an adult is quite characteristic of nonindustrialized society (Medaets, this issue; Odden 2007: 501; Odden and Rochat 2004:47; Polak 2013). In contrast, the Vygostkian model of development (e.g., Wertsch 1985:161) applies much better in WEIRD society, where scaffolding within the zone of proximal development is far more frequent and extensive.

Conversation in the family circle freely passes among adults, but children are expected to quietly observe (Lancy and Grove 2010:153; Martini and Kirkpatrick 1992:203; Penn 2001:91; Polak 2012:88). As children work and learn, no one offers verbal instruction, rather "conversation and questions... usually occur for the sake of sharing necessary information" (Paradise and Rogoff 2009:118). Aka Pygmy children "seldom ask questions about how to do things... parents are proximal and very available for social leárning, especially before age five" (Hewlett et al. 2011:1173). Young children can expect some attention from family membersas long as they are focused on the task at hand (Weisner 1989:78). Indeed, merely by approving/disapproving children's early attempts, older family members can dramatically improve their efficiency as social learners (Castro and Toro 2004). This thumbs up/down may be the most common form of "instruction" provided to the child (Michelet, this issue). Little describes a six-year-old Asabano girl emulating her mother's construction of a string bag. If uncertain where to put the next knot, the girl asks "Here?" and the mother “would respond with a grunt indicating 'yes' or 'no.' [if the child were] tying a knot at the wrong place, her mother would preempt her [by saying] nothing more than 'no"” (Little 2011:154).

The Michelet and Medaets' articles in this issue (see also Polak 2012:104, 2013) introduce yet another dimension to the comparative study of parental ethnotheory regarding children's learning and carrying out chores. In these studies, we see parents systematically erecting obstacles in the path of child novices (Maori-Metge 1984:7; Ngoni-Read 1959:78). Bamana, Mongol, and Lower Tapajós River adults, respectively, offer somewhat different goals for this strategy, and the three societies are distinctive in other aspects of their interaction with young helpers. But the finding that children may be, at least initially, thwarted, even teased in their attempts to participate in adult work are in accord with recent experimental work in the United States, which shows that children who have experienced some ostracism are more diligent at copying a model (Watson-Jones et al. 2014).

\section{Work and Identity}

As the child builds its repertoire of useful skills and finds his or her niche in the family ecology, he or she is simultaneously constructing his or her identity (Lave and Wenger 1991:55). For example, Tchokwé "children are identified through the roles they assume... kambumbu are children ... who help parents in the field" (Honwana 2006:41-42). 
210 ETHOS

In the Giriama language the term for a child roughly 2 through 3 years in age is kabobo kubuma madzi: a youngster who can be sent to fetch a cup of water... A girl, from about 8 years until approximately puberty, is muboho wa kubunda, a child who pounds maize; a boy of this age is a muboho murisa, a child who herds. (Wenger 1989:98)

There are also many examples of adults sponsoring minor rites of passage to acknowledge the child's movement through the chore curriculum. Such celebrations include: a Kaoka boy's first pig (Hogbin 1969:39); Wogeo families assigning a child their first garden plot (Hogbin 1970:139-140); and a Vlach six-year-old being given his first shepherd's crook (Campbell 1964:156). "When an [Mbuti] boy kills his first "real animal," he is immediately acclaimed as a hunter... [and honored by cicatrization] ... an operation performed ... by one of the 'great hunters"' (Turnbull 1965:257; see also !Kung-Howell 2010:35). In the article by Michelet, we get a glimpse of three-year-old Batuhan's first acknoyledgement as a "hardworking person" (this issue).

Chores also play an important role in the differentiation of gender, especially before the appearance of secondary sex characteristics. Goats are tended by Touareg boys and girls, but only boys tend camels (Spittler 1998). The Tarong equivalent of the camel is the carabao, or water buffalo, tended only by boys (Whiting and Edwards 1988:224). Weaving is the province of women among Akwete Igbo, but for the Baulè, only males weave (Aronson 1989). As for most hunter-gatherers, Hadza girls gather and boys hunt (Marlowe 2010). Almost universally, girls are preferred as caretakers for younger siblings, while sons are conscripted for this chore only when a daughter is unavailable (Ember 1973:425-426; Stieglitz et al. 2013:6).

Another frequent observation is that girls consistently spend more of their day doing chores, including sib-care, høusework, and gardening. Boys spend relatively more of their time playing. Indeed, boys, in many societies, are defined as much by their freedom from work (relative to girls) as by the specific work they do (Little and Lancy, this issue; Stieglitz et al. 2013:7-8). "These differences are seen from age three onwards" (Edwards 2005:87). Boys range farther afield, running errands, patrolling distant fields, and hunting in the bush. In my observations, boy's "work" often looks more like play, while girl's work seems more focused and purposeful. Hadza children's foraging illustrates the way in which girls "get serious" at an age when boys are acting rather frivolously, with significant consequences. From the age of 10, girls are gathering more food than they consume. Boys, on the other hand, concentrate on more exotic foods such as honey and small game, but their yields are low (Blurton-Jones et al. 1997:291).

\section{Development in the Chore Curriculum}

A developmental perspective reveals change over time in children's involvement and competence. Children are usually permitted to learn at their own pace and numerous ethnographers have noted that play is frequently infused into the work. ${ }^{9}$ To use a modern expression, "learning should be fun." Children's foraging for the Zafimaniry is seen as 
an adventurous but not a serious form of activity ... a form of play. Consequently the product of such activity, although it is very important nutritionally and economically it is not, nor in their evaluation should it be, taken seriously. ${ }^{10}$ (Bloch 1988:28)

The child's engagement and progress is often facilitated because tasks or projects can be broken down into smaller, child-sized fragments, creating a staged or stepped curriculum. There is usually a good fit between the child's developing abilities and some subset of the overall task inventory. Children eagerly pursue more challenging undertakings without prompting. They provide their own motive power. Because they are in company with, and supervised by, somewhat older siblings (Weisner and Gallimore 1977:170), young learners have access to excellent role models whose competence (speed, strength, pacing) may be only slightly more advanced than their own (Lancy and Grove 2010:156-157; Maynard and Tovote 2010; Polak 2003).

Agriculture offers tasks as simple as chasing birds from the ripening crop (Grindal 1972:29; Lancy 1996:146) to leading a team of oxen (Polak 2012:105). The child is integrated into the chore curriculum at the appropriate stage. One sees a Guara trio working in the garden: "While the man makes holes with his digging stick, and his wife places seeds carefully in each hole, the child follows, using the feet to push the earth back over the hole" (Ruddle and Chesterfield 1977:71). Fore (Eastern Highlands, PNG) girls' [make-believe] gardening is followed by clumsy and even destructive attempts to emulate the gardening activities of their elders. Gradually, these efforts "more and more resemble the . . sustained gardening [that is] the basis of the Fore way of hife" (Sorenson 1976:200). Kwoma (Sepik Region, PNG) parents go further by actually setting aside an area of the garden for the child to work on their own, thereby protecting their own gardens from harm. Likewise, the child may be given their own scaled-down collecting calabash, hoe, or machete. Any produce from this mini-garden is "put in a separate bin in the family storehouse as the child's private property" (Whiting 1941:46; Hogbin 1969:39). Note in the following transcript from the Bamana how the chores in a family bean-harvesting project can be matched to children's skill and persistence:

Three-year-old Daole ... begins to pluck beans from the tendrils. After he has filled the lid with a handful of beans, his interest fades [and he] carelessly leaves the lid with the beanslying on the ground and goes looking for some other occupation ... Five-year-old Sumala ... looks out for a corner not yet harvested and picks as many beans as will fill his calabash ... [he] keeps on doing this for more than one-and-a-half hours ... Eleven-year-old Fase has been busy harvesting beans ... since morning. He works as fast as ... his father and grown-up brother ... and only takes a rest when they [do] ... Fase ... even takes on the role of supervising his younger brothers and checks their performance from time to time. (Polak 2003:130, 132, emphasis added)

The Bamana illustrate Weisner's notion of "chains of support" in which each member of the family work group supports and guides those who are slightly less advanced on the competency scale (Weisner 1996:308). Children not only improve their skills, they assume greater responsibility for supervising the less skilled. Excellent examples of the stepped nature of the chore curriculum can be found for hunting (Goodwin and Goodwin 1942:475), 


\section{ETHOS}

handling a canoe (Lancy 2012a 26-27), herding (Spittler 1998), running errands (Nerlove et al. 1974:276), and weaving (Dilley 1989), among others.

In spite of the fact that most children are permitted to develop work skills, and a worker's mindset, at their own pace - with many playful digressions - there is a great variability across the ethnographic record in expectations for the child's progress towards adult levels of competence and productivity. Tibetan children of six or seven are expected to be fully competent to herd livestock in distant pastures (Gielen 1993:426). !Kung children, in contrast, must be left behind in camp and may not begin their foraging careers until their teens (Hames and Draper 2004:334). The !Kung homeland in the Kalahari desert is extremely difficult to navigate, and foragers face the threat of predation. Children cannot accompany their parents and learn from their example because of the burden their care and provisioning would impose on the foragers. With the Amazonian-based Huaorani, the terrain is somewhat more benign, and even young children are welcome on foraging expeditions (Rival 2000:116). On the island of Mer in the Torres Straits, unsupervised, untutored children can collect edible marine life from the shoreline and shallows. They can be seen "spearfishing with toddler-sized spears as soon as they begin walking, using them at first to spear sardines along the foreshore for bait" (Bird and Bliege Bird 2002:262). A survey of children's contribution to subsistence in 16 communities across the spectrum of subsistence types showed great variation from approximately one-half hour of work/day (!Kung) to 9.6 hours (Ariaal pastoralists) (Kramer and Greaves 2011). The variability within subsistence types was also wide:

Forager children show both high and low participation in economic activities, suggesting that children's work effort yaries with factors other than whether a child is a forager, agriculturalist or pastoralist per se. (Kramer and Greaves 2011:308; see also Hewlett 1996)

Another source of variability arises from contrastive ethnotheories that guide parents in their interaction with children. In some cases, children are not seen as making much of a contribution to the larder and parents grant them great freedom and leisure. !Kung children, for example, often "pitch-in" to fetch water or firewood, process Mongongo nuts and animal hides, and prepare meals, but "it is well understood that children do these chores only if they feel like it" (Howell 2010:31). In other societies, the family's survival and prosperity are materially affected by children's work, and "parents exercise a considerable amount of coercive control over [their] time" (Bock 2002:211; Stieglitz et al. 2013).

\section{Children's Contribution to the Domestic Economy}

Across the spectrum of societies, we can detect two evident clusters around the issue of children's contribution to the family economy. WEIRD societies expect little or no contribution to the family economy. Children are indulged and dependent. A handful of foraging societies where children's development is never rushed and infants wean themselves (Lancy 2015:66-70) also form part of this cluster. Children may be valued "for their ability to make life more enjoyable" (!Kung-Shostak 1981:179), rather than the Biblical view where children are seen as resources to be used by adults "like livestock or crops" (Horn and 
Martins 2009:43). Societies where children are free to be children are highly egalitarian, and the idea of trying to influence another-by teaching them, for example-is unthinkable (Lewis 2008). "The Yequana do not interfere with children's pursuits believing that "the child's will is his motive force" (Gray 2009:507). Punishment for failing to do one's chores is unknown (Endicott 1992:286). Youth gradually acquire the necessary skills to survive, but they are not relied upon to any degree as "providers" until their teens.

At the other extreme are societies where the developmental span may be compressed.

Developmental milestones such as weaning (Hewlett et al. 2011:1172) or walking (Súper 1976:290) may be accelerated. Children may be threatened with all sorts of terrors to discourage them from nursing (Williams 1969). The weaned and "rejected" toddler (Weisner and Gallimore 1977:176) can expect some attention from family members as long as he or she is focused on the task at hand (Weisner 1989:78). That is, the primary means by which the child may now satisfy its need to fit in is by being helpful. Clearly societies where LOPI is the model for children's behavior fit this cluster. How high the bar may be raised, and how quickly, may vary, but the child readily settles into a routine of providing reliable services such as carrying water or firewood, tending livestock, and looking after a younger sibling. This is particularly true for girls, who become valued assistants to their mothers. The transition into middle childhood (Lancy and Grove 2011) is frequently marked by the recognition of greater maturity or sense of responsibility and diligence. Many of the qualities that are attached to native terms for intelligence (Lancy 2012a:34) suggest that the child is much better at perspective taking and can better anticipate another's intentions and desires. They contribute appropriately without bidding or guidance (Lancy 2015:201).

The distinctiveness of these two patterns has been significantly advanced by the work of Barry Hewlett and his colleagues with systematic comparisons between Central African children growing up as (Aka) foragers and those born into neighboring villages of (Ngandu) farmers. While Aka infants wean themselves, and are largely free to manage their own lives, the Ngandu are weaned early, and adults exert control over how they spend their time (Hewlett et a1. 2011). At six, an Ngandu child's chores include washing clothes, fetching water, preparing food, sweeping the house, and field-work. To accelerate the transition from playing to working, a parent may instruct the child: "she took ... a big piece of maize and she showed me, holding my hand, how to plant the corn" (Hewlett 2013:69). ${ }^{10}$ An older Ngandu woman recalls:

I remember ... when I was young and I went to the river to fish with my friends and we caught fish to eat. When I got back my mother said to me, "Why did you go fish? You do not work here at the house when I need you, and go play with your friends instead, so go away and live somewhere else." (Hewlett 2013:75)

Punishing the child for a failure to work diligently is often noted (Levine 1965:266; Ochs and Izquierdo 2009:395). 
These differences in the proportion of children's lives spent working have also been gauged by quantitative analyses. Kramer compared gross levels of productivity as a function of age among Mayan farming children and their counterparts in two South American foraging groups. The Mayan children reached an equilibrium of producing as much as they consumed by age 13, whereas foraging children took five to 10 years longer (Kramer 2005:135). At the same time, such studies also reveal a great deal of variability within these clusters. So while Mayan teens spend on average 4.5 hours a day working (Kramer 2002:312), for teens growing up in Javanese and Nepalese peasant communities, the figures range from eight to 11 hours a day (Nag et al. 1978:294). If we include historical material in this discussion, we'll see children providing critical labor input from an early age. By the 1720 s, four-year-olds were employed in French textile mills, and a hundred years later in Lancashire, one-quarter of all the 10-15-year-old girls were working in cotton mills (Sommerville 1982:250). There is seasonal variation as well. During rice harvest season, Tsimané boys are more likely delegated domestic chores to replace parents or older siblings who are busy with the harvest (Stieglitz et al. 2013:237).

\section{Advancing our Understanding of Children and Work}

To further advance our understanding of children and work, a number of issues command attention. The literature suggests that children in nonelite communities in both rural (Paradise and Rogoff 2009) and urban (e.g., Orellana 2001) areas willingly pitch in to help and do so on the basis of voluntary, self-guided learning of the necessary skills. However, the close collaboration between tolerant experts and clumsy novices characteristic of the LOPI model developed by Rogoff and colleagues may not be universal, as shown in the articles by Little and Lancy, Medaets, and elsewhere (Naji 2012:374; Polak 2013; Reichard 1934:38). On Samoa, the distance imposed by rank makes it difficult for parents, or even older sibling caretakers, to actively collaborate with young learners, but children of about the same age and rank do learn through collaboration-how to fish, for example (Odden 2007:222). In most societies, children are granted the autonomy to learn independently without the need for close supervision or teaching. A frequent observation is that very young children are given or permitted to play with sharp and/or dangerous tools so they can learn to use them (Lancy 2016), for example. Are parents always hands-off, or do they intervene in the process of chore learning and execution? For example, while children appear to be highly motivated to achieve competence, their "reach may exceed their grasp." In a Philippine barrio, children are expected to pitch in, and many "said they had been repeatedly punished for doing things they had been told were too difficult for them" (Nydegger and Nydegger 1963:851). The articles by Michelet and Medaets also discuss impediments that may be placed in the learner's path and the reasons for them.

The succeeding studies in this issue will take us further towards an understanding, not just of the work that children do, but of the cultural practices and ideals that guide their acquisition of these skills. We will use children's work as a lens to view children's development in culture, their roles as participants in the domestic economy, and parental perspectives or ethnotheories, as well as actions taken by them with respect to children's work and 
learning. Additionally, two of the articles (Michelet and Medaets) discuss the relationship between culturally constructed patterns underlying children's learning to work and broader socialization goals. As a critical adjunct to this effort, we will discuss methodological issues that arise in the pursuit of these questions (Little and Lancy, this issue).

\section{DAVID F. LANCY is Emeritus Professor of Anthropology at Utah State University.}

\section{Notes}

1. The WEIRichD acronym excludes poor and working-class children in the developed countries. Although these children's contribution to the domestic economy has not been thoroughly documented, at least one study in the United States demonstrates that children in families of recent Latin American migrants contribute a great deal of time and resourcefulness to supporting their families (Orellana 2001).

2. It might be noted that, even today, one can find remote villages across Europe and the United States where small-scale, mixed farming prevails. In those communities, children are fully integrated into the family workforce from an early age and chores trump schooling (Brykczyński 2014; Schmid 2011; see also Zepeda and Kim 2006).

3. It is generally assumed that observation and imitation (or mimesis) are inseparable. Children, after observing a process, will either attempt to replicate that process directly or incorporate it into their make-believe. A long-time student of learning refers to human children as "imitation machines" (Tomasello 1999:52).

4. There is a lack of consensus on how to define instruction or teaching in studying children's learning in traditional societies. In the group of scholars included in this issue, we have been guided by the following:

Based on our interpretation of previous attempts to define teaching, we propose the following working definition. There are two corollary conditions that must be met:

1. The teacher must incur costs (taking time away from their work or using nonrecoverable materials), and these "costs to teachers of facilitating learning are outweighed by the long-term fitness benefits they accrue once pupils have learned" (Thornton and Raihani 2008:1823).

2. Teaching will not occur or is unlikely where the learner is able to acquire the requisite knowledge or skill in the absence of teaching (Thornton and Raihani 2008:1823).If these conditions are met then:

3. Teaching involves the intent of the teacher to alter/enhance the knowledge or competence of the learner.

4. The teacher takes steps to secure the learner's intention to learn.

5. The learner is aware of the teacher's intention and engages with or attends to the "lesson" (3-5; cf. Olson 2009:3).

5. Children's work can be analytically assigned to one of three clusters: chores, craft production, and apprenticeship. The latter two clusters are carefully reviewed elsewhere (Lancy 2012a, 2012b) and won't concern us.

6. Hunting - where women and children are sometimes prevented for various reasons from participating-is an instructional exception. Boys may take much longer to become proficient hunters because opportunities to learn from observation are limited (Sugiyama and Chacon 2005:259).

7. $\mathrm{xxxx}$

8. The Baining (New Britain Island, PNG) actively discourage play and introduce children to gardening as early as feasible (Fajans 1997:92).

9. This is an example of a cultural model exerting "directive force."

10. In the PNG Highlands, men are socially superior to women, and the workload is distributed accordingly. Asabano boys' development is unrushed, and they are free from any coercion to help out. Girls' development, by 


\section{ETHOS}

contrast, is accelerated, and their behavior is more tightly controlled. They become workers quite early (Little 2008: 38).

\section{References Cited}

Alcalá, Lucía, Barbara Rogoff, Rebeca Mejía-Arauz, Andrew D. Coppens, and Amy L. Dexter

2014 Children's Initiative in Contributions to Family Work in Indigenous-Heritage and Cosmopolitan Communities in Mexico. Human Development 57:96-115.

Aronson, Lisa

1989 To Weave or Not to Weave: Apprenticeship Rules among the Akwete Igbo of Nigeria and the Baulé of the Ivory Coast. In Apprenticeship: From Theory to Method and Back Again. Michael W. Coy, ed. Pp. 149-162. Albany: State University of New York Press.

Bandura, Albert 1977 Social Learning Theory. Englewood Cliffs, NJ: Prentice-Hall.

Bliege Bird, Rebecca, and Douglas W. Bird

2002 Constraints of Knowing or Constraints of Growing? Fishing and Collection by the Children of Mer. Human Nature 13:239-267.

Bloch, Maurice E. F.

1988 How We Think They Think: Anthropological Approach to Cognition, Memory, and Literacy. Boulder, CO: Westview Press.

Blurton-Jones, Nicholas G., Kristen Hawkes, and James F. O'Connell

1997 Why Do Hadza Children Forage? In Uniting Psychology and Biology: Integrative Perspectives on Human Development. Nancy L. Segal, Glenn E. Weisfeld, and Carol C. Weisfeld Carol, eds. Pp. 279-313. Washington, DC: American Psychological Association.

Bock, John

2002 Evolutionary Demography and Intrahousehold Time Allocation: School Attendance and Child Labor Among the Okavango Delta Peoples of Botswana. American Journal of Human Biology 14:206-221.

Bock, John, and Sara E. Johnson 2004 Subsistence Ecology and Play Among the Okavango Delta Peoples of Botswana. Human Nature 15:63-82.

Bolin, Inge 2006 Growing up in a Culture of Respect: Childrearing in Highland Peru. Austin: University of Texas Press.

Bril, Blandine

1986 Mali (Africa). In Themes in Motor Development. Harold Thomas, Anthony Whiting, and Michael G. Wade, eds. Pp 315-326. Dordrecht, Netherlands: Martinus Nijhoff.

Broch, Harald B. 1990 Growing up Agreeably: Bonerate Childhood Observed. Honolulu, HI: University of Hawaii Press.

Brykczyński, Jan 2014 Boiko. Warsaw, Poland: Brykczyński.

Bourdillon, Michael, and Gerd Spittler

2012 Introduction. In African Children at Work: Working and Learning in Growing Up. Gerd Spittler and Michael Bourdillon, eds. Pp. 1-22. Berlin: LitVerlag.

Campbell, John K.

1964. Honour, Family, and Patronage: A Study of Institutions and Moral Values in a Greek Mountain Community. Oxford: Clarendon Press.

Castro, Laureano, and Miguel A. Toro 2004 The Evolution of Culture: From Primate Social Learning to Human Culture. Proceedings of the National Academy of Sciences 101:10235-10240.

Chick, Garry

2010 Work, Play and Learning. In The Anthropology of Learning in Childhood. David F. Lancy, John Bock, and Suzanne Gaskins, eds. Pp 119-144. Lanham, MD: AltaMira.

Clement, Priscilla F.

1997 Growing Pains: Children in the Industrial Age, 1850-1890. New York: Twayne.

Danielsson, Bengt

1952 The Happy Island. F. H. Lyon, trans. London: George Allen and Unwin.

de Waal, Franz

2001 The Ape and the Sushi Master. New York: Basic Books.

Dilley, Roy M.

1989 Secrets and Skills: Apprenticeship Among Tukolor Weavers. InApprenticeship: From Theory to Method and Back Again. Michael W. Coy, ed. Pp. 181-198. Albany: State University of New York Press. 
218 ETHOS

Hogbin, H. Ian

1969 A Guadalcanal Society: The Kaoka Speakers. New York: Holt, Rinehart, and Winston.

1970 A New Guinea Childhood: From Weaning Till the Eighth Year in Wogeo. In From Child to Adult, John Middleton, ed. Pp. 134-162. Garden City, NY: Natural History Press.

Honwana, Alcinda

2006 Child Soldiers in Africa. Philadelphia: University of Pennsylvania Press.

Horn, Cornelia B., and John W. Martens

2009 "Let the Little Children Come to Me:" Childhood and Children in Early Christianity. Washington, DC: Catholic University Press.

Howell, Nancy

2010 Life Histories of the Dobe !Kung: Food, Fatness, and Well-Being Over the Life Span. Berkeley, CA: University of California Press.

Ingold, Tim

2001 From the Transmission of Representations to the Education of Attention. In The Debated Mind: Evolutionary Psychology Versus Ethnography. Harvey Whitehouse, ed. Pp. 113-153. Oxford: Berg.

Jenness, Diamond

1922 The Life of the Copper Eskimos. Report of the Canadian Arctic Expedition, 1913-18, Vol. 12(A). Ottawa, Canada

Katz, Cindi

1986 Children and the Environment: Work, Play, and Learning in Rural Sudan. Children's Environments

Keller, Heidi Quarterly 3:43-51.

2007 Cultures of Infancy. Mahwah, NJ: Erlbaum.

Kenyon, Dienje, and Charles D. Arnold

1985 Toys as Indicators of Socialization in Thule Culture. In Status, Structure and Stratification: Current Archaeological Reconstructions. Marc Thompson, Maria Teresa Garcia, and Francois J. Kense, eds. Pp. 347-353. Calgary, AL: Archaeological Association of the University of Calgary.

Klein, Wendy, and Majorie H. Goodwin

2013. Chores. In Fast Forward Families: Home, Work and Relationships. Elinor Ochs, and Tamar KremerSadlik, eds. Pp. 111-129. Los Angeles: University of California Press.

Kline, Michelle A., Robert Boyd, and Joseph Henrich

2013 Teaching and the Life History of Cultural Transmission in Fijian Villages. Human Nature 24:351-374.

Konner, Melvin J.

2010 The Evolution of Childhood: Relationships, Emotion, Mind. Cambridge, MA: Belknap Press.

Kramer, Karen L.

2002 Variation in Juvenile Dependence: Helping Behavior Among Maya Children. Human Nature 13: 299-325.

2005 Maya Children: Helpers on the Farm. Cambridge, MA: Harvard University Press.

Kramer, Karen L., and Russell D. Greaves

2011 Juvenile Subsistence Effort, Activity Levels, and Growth Patterns. Human Nature 2:303-326.

Kremer-Sadlik, Tamar, Carolina Izquierdo, and Marilena Fatigante

2010 Making Meaning of Everyday Practices: Parents' Attitudes Toward Children's Extra-Curricular Activities

in the United States and in Italy. Anthropology of Education Quarterly 4:35-54.

Lancy, David F.

1996 Playing on the Mother Ground: Cultural Routines for Children's Development. New York: Guilford.

2007 Accounting for Variability in Mother-Child Play. American Anthropologist 109:273-284.

2012a The Chore Curriculum. In African Children at Work: Working and Learning in Growing Up. Gerd Spittler and Michael Bourdillion, eds. Pp 23-57. Berlin: Lit Verlag.

2012b "First You Must Master Pain:" The Nature and Purpose of Apprenticeship. Society for the Anthropology of Work Review 33:113-126.

2015 The Anthropology of Childhood: Cherubs, Chattel, Changelings. 2nd edition. Cambridge: Cambridge University Press.

2016 Playing with Knives: The Socialization of Self-Initiated Learners. Child Development.

Lancy, David F., and M. Annette Grove

2010 The Role of Adults in Children's Learning. In The Anthropology of Learning in Childhood. David Lancy, Suzanne Gaskins, and John Bock, eds. Pp 145-180. Lanham, MD: Alta-Mira Press.

2011 "Getting Noticed": Middle Childhood in Cross-Cultural Perspective. Human Nature 22:281-302.

Lancy, David F., Suzanne Gaskins, and John Bock, eds.

2010 The Anthropology of Learning in Childhood. Lanham, MD: Alta-Mira Press.

Lave, Jean, and Etienne Wenger

1991 Situated Learning: Legitimate Peripheral Participation. Cambridge: Cambridge University Press. 


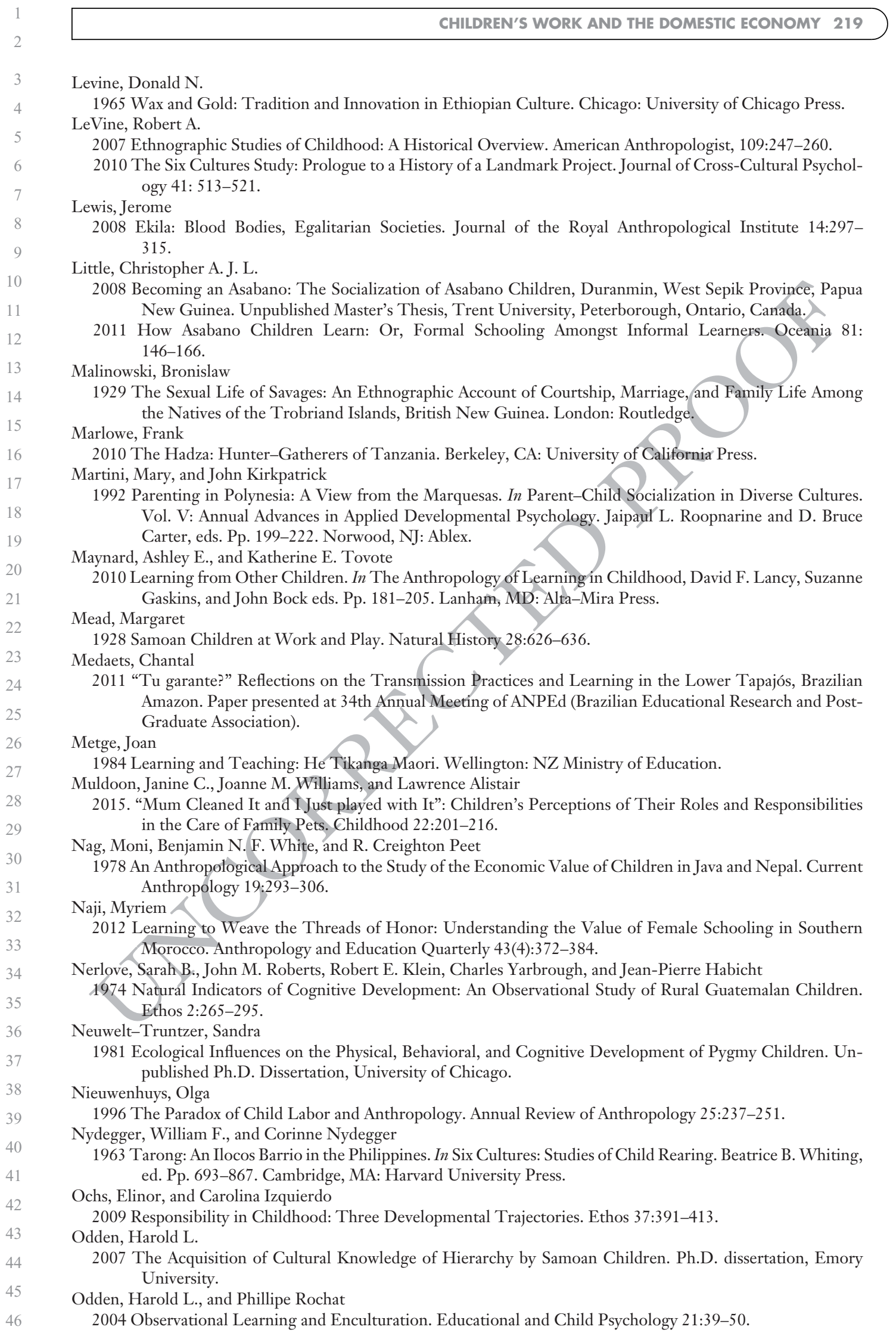


220 ETHOS

Ohmagari, Kayo, and Fikret Berkes

1997 Transmission of Indigenous Knowledge and Bush Skills among the Western James Bay Cree Women of Subarctic Canada. Human Ecology 23:197-222.

Olson, David R.

2009. Some preliminaries to the natural history of pedagogy. In Fostering Change in Institutions, Environments and People. David Berliner and Helga Kupermintz, Pp. 1-13.New York: Routledge.

Orellana, Marjorie F.

2001 The Work Kids Do: Mexican and Central American Immigrant Children's Contributions to Households and Schools in California. Harvard Educational Review 71:366-389.

Ottenberg, Simon

1968 Double Descent in an African Society: The Afikpo Village-Group. Seattle: University of Washington Press.

Paradise, Ruth, and Barbara Rogoff

2009 Side by Side: Learning by Observing and Pitching In. Ethos 37:102-138.

Penn, Helen

2001 Culture and Childhood in Pastoralist Communities: The Example of Outer Mongolia. In Conceptualizing Child-Adult Relations. Leena Alanen and Berry Mayall, eds. Pp. 86-98. Abington, UK: Routledge.

Polak, Barbara

2003 Little Peasants: On the Importance of Reliability in Child Labour. In Le travail en Afrique Noire: Reprál'Ésentations et Pratiques Époque Contemporaine. Hèléne d'Almeida-Tópor, Monique Lakroum, and Gerd Spittler, eds. Pp. 125-136. Paris, France: Karthala.

2012 Peasants in the Making: Bamana Children at Work. In African Children at Work: Working and Learning in Growing Up. Gerd Spittler and Michael Bourdillon, eds. Pp. 87-112. Berlin: LitVerlag.

2013 Cooperation Matters: How Malian Peasants Charge Their Children with Agricultural Tasks. Paper presented at panel on Parental Views on Teaching, Children's Acquisition of Critical Life Skills and Their Contribution to the Domestic Economy. Society for Psychological Anthropology Biennial meeting. San Diego, CA.

Quinn, Naomi

2005 Universals of Child Rearing. Anthropological Theory 5:477-516.

Qvortrup, Jens

1994 Childhood Matters: An Introduction. In Childhood Matters: Social Theory, Practice, and Politics, Jens Qvortrup, Marjatta Bardy, Giovanni Sgritta, and Helmut Wintersberger, eds. Pp 1-23. Brookfield, VT: Avebury.

Read, Margaret

1959 Children of Their Fathers: Growing Up Among the Ngoni of Nyasaland. New Haven, CT: Yale University Press.

Reichard, Gladys

1934 Spider Woman: A Story of Navaho Weavers and Chanters. New York, NY: Macmillan.

Rheingold, Harriet

1982 Little Children's Participation in the Work of Adults, A Nascent Prosocial behavior. Child Development

Rival, Laura $53: 114-125$.

2000 Formal Schooling and the Production of Modern Citizens in the Ecuadorian Amazon. In Schooling the Symbolic Animal: Social and Cultural Dimensions of Education, Bradley A.U. Levinson, ed. Pp.108-122. Lanham, MA: Rowman and Littlefield.

Rogoff, Barbara

2003 The Cultural Nature of Human Development. New York: Oxford University Press.

2014 Learning by Observing and Pitching In to Family and Community Endeavors: An Orientation. Human Development 57:69-81.

Rogoff, Barbara, Jayantha Mistry, Artin Göncü, and Christine Mosier

1993 Guided Participation in Cultural Activity by Toddlers and Caregivers. Monographs of the Society for Research in Child Development 58(7, Serial No. 236).

Ruddle, Kenneth, and Ray Chesterfield

1977 Education for Traditional Food Procurement in the Orinoco Delta. Los Angeles: University of California Press.

Schmid, Alice

2011. Die Kinder vom Napf. Zürich: Switzerland. Ciné A.S. GmbH

Shennan, Stephen J., and James Steele

1999 Cultural Learning in Hominids: A Behavioral Ecological Approach. In Mammalian Social Learning: Comparative and Ecological Perspectives. Hilary O. Box and Kathleen R. Gibson, eds. Pp. 367-388. Cambridge: Cambridge University Press. 
Sommerville, John C.

1982 The Rise and Fall of Childhood. Beverly Hills, CA: Sage.

Sorenson, E. Richard

1976 The Edge of the Forest: Land, Childhood and Change in a New Guinea Protoagricultural Society. Washington, DC: Smithsonian Institution Press.

Spittler, Gerd

1998 Hirtenarbeit. Köln, Germany: Rüdiger Köppe.

Stieglitz, Jonathan, Michael Gurven, Hillard Kaplan, and Paul L. Hooper

2013 Household Task Delegation among High-Fertility Forager-Horticulturalists of Lowland Bolivia. Current Anthropology 54:232-241.

Strauss, Claudia

1992 Models and Motives. In Human Motives and Cultural Models, Roy d'Andrade and Claudia Strauss, eds. Pp. 1-20. Cambridge: Cambridge University Press.

Sugiyama, Lawrence S., and Richard Chacon

2005 Juvenile Responses to Household Ecology among the Yora of Peruvian Amazonia. In Hunter Gatherer Childhoods: Evolutionary, Developmental, and Cultural Perspectives, Barry S. Hewlett and Michael E. Lamb, eds. Pp. 237-261. New Brunswick, NJ: Aldine Transaction.

Super, Charles M.

1976 Environmental Effects on Motor Development: The Case of “African Infant Precøcity.” Developmental Medicine and Child Neurology 18:561-567.

Super, Charles M., and Sara Harkness

1986 The Developmental Niche: A Conceptualization at the Interface of Child and Culture. International Journal of Behavior Development 9:545-569.

Tayanin, Damrong, and Kristina Lindell

1991 Hunting and Fishing in a Kammu Village. Studies in Asian Topics No. 14. Copenhagen, Denmark: Curzon Press.

Thornton, Alex, and Nichola J. Raihani 2008 The Evolution of Teaching. Animal Behaviour 75:1823-1836.

Tomasello, Michael 1999 The Cultural Origins of Human Cognition. Cambridge, MA: Harvard University Press.

Turnbull, Colin M. 1965 The Mbuti Pygmies: An Ethnographic Suryey. New York: American Museum of Natural History.

Warneken, Felix, and Michael Tomasello

2006 Altruistic Helping in Human Infants and Young Chimpanzees. Science 311:1301-1303.

Watson-Jones, Rachael E., Christine H. Legare, Harvey Whitehouse, and Jennifer M. Glegg

2014 Task-Specific Effects of Ostracism on Imitative Fidelity in Early Childhood. Evolution and Human Behavior 35:204 -210.

Weisner, Thomas S.

1989 Cultural and Universal/Aspects of Social Support for Children: Evidence from the Abaluyia of Kenya. In Children's Social Networks and Social Supports, Deborah Belle, ed. Pp. 70-90. New York: John Wiley.

1996 Why Ethnography Should Be the Most Important Method in the Study Of Human Development. In Ethnography and Human Development: Context and Meaning in Social Inquiry. Richard Jessor, Anne Colby, and Richard W. Shweder, eds. Pp. 305-324. Chicago: University of Chicago Press.

Weisner, Thomas S., and Ronald Gallimore 1977 My Brother's Keeper: Child and Sibling Caretaking. Current Anthropology 18:169-190.

Wenger, Martha

1989 Work, Play and Social Relationships Among Children in a Giriama Community. In Children's Social Networks and Social Supports, Deborah Belle, Ed. Pp. 91-115. New York: Wiley.

Wertsch, James V.

1985 Vygostsky and the Social Formation of Mind. Cambridge, MA: Harvard University Press.

White, Robert W.

1959 Motivation Reconsidered: The Concept of Competence. Psychological Review 66:297-333.

Whiting, Beatrice B., and Carolyn P. Edwards

1988 Children of Different Worlds: The Formation of Social Behavior. Cambridge, MA: Harvard University Press.

Whiting, Beatrice B., and John W. M. Whiting

1975 Children of Six Cultures: A Psycho-Cultural Analysis. Cambridge, MA: Harvard University Press.

Whiting, John W. M.

1941 Becoming a Kwoma. New Haven, CT: Yale University Press. 
Willerslev, Rane

2007 Soul Hunters: Hunting, Animism, and Personhood Among the Siberian Yukaghirs. Berkley: University of California Press.

Williams, Thomas R.

1969 A Borneo Childhood: Enculturation in Dusun Society. New York: Holt, Reinhart, and Winston.

Zepeda, Lydia, and Jongsoog Kim

2006 Farm Parents' Views on Their Children's Labour on Family Farms: A Focus Group Study of Wisconsin Dairy Farmers. Agriculture and Human Values 23:109-121. 


\section{Author Queries}

Q1: Author: Please confirm that given names (red) and surnames/family names (green) have been identified correctly.

Q2: Author: Please provide endnote 7. 